\title{
Carbon C 13 Phytofluene
}

National Cancer Institute

\section{Source}

National Cancer Institute. Carbon C 13 Phytofluene. NCI Thesaurus. Code C98834.

A 40-carbon hydrocarbon precursor of carotenoids radiolabeled to carbon C 13 and potentially used for tracer purposes of phytofluene in vivo. Upon administration, phytofluene is taken up and accumulates in various tissues. Upon imaging of the radioisotope, the distribution patterns and metabolism of phytofluene can be further elucidated which may aid in the understanding of the bioactivity of this agent. Phytofluene is a colorless precursor of many carotenoids, including the antioxidant lycopene. 